\title{
Guest editorial: Management, social responsibility and sustainability in tourism: issues and practices
}

\author{
Tonino Pencarelli - Umberto Martini - Alfonso Vargas-Sánchez
}

The idea of launching a call to create a special issue on the subjects of sustainability and social responsibility in tourism was born during a meeting with the thematic group "Tourism and Culture Management" of the Italian Management Society (SIMA) on the occasion of the conference of Rome La Sapienza organized by SIMA and Sinergie, Italian Journal of Management, on 20-21 June 2019.

The theme of the special issue was initially also inspired by the topics covered during that Conference, the title of which was "Management and sustainability: creating shared value in the digital era". In reality, the theme of sustainability in tourism has long been common to scholars of tourism management and fascinates us as curators of this special issue too. Indeed, we are aware that the problems of global pollution, climatic upheavals, population health and, more generally, all the challenges placed at the center of the 2030 agenda of the United Nations Organization (UN) are fundamental for orienting economic activities towards the paradigm of sustainability. A paradigm that suggests the managerial conduct of companies aimed at respecting the three dimensions of sustainability, that are the environmental, social and economic sustainability and at pursuing therefore strategies of corporate social responsibility. In tourism, the issue of sustainability is sometimes considered an oxymoron, as it is inevitable that the movement of enormous flows of people from their places of residence to tourist destinations will not always have positive impacts on the environment, on the social communities and on the creation of economic value for the players of the sector.

In the field of tourism, in fact, the challenge of sustainability and the need to develop a management for sustainability are of extreme relevance, due to the various impacts of mass tourism on cities, territories, landscapes and, more in general, on eco-systems. In many cases, tourism affects social stability and the vision of the local residents about its role, given the problems and the damages due to the uncontrolled mass-tourism impacts on the local community and on the environment. As a consequence, the matter of sustainability concerns both firms and territories, many of which are testing new organizations based on public/private partnerships with the aim to include the consideration of the social and environmental impacts in the evaluation of their economic decisions. Only a deep and integrated consideration of the impacts of tourism as a whole in a multi-disciplinary approach, appears to guarantee the sustainability of tourism, both in cities and in territorial destinations based on natural resources and landscape.

Given the evolution of tourism and the rise of new sensibilities in the current society, this special issue is aimed at collecting papers concerning 
sinergie Vol. 39, Issue 1, 202

theoretical frameworks, applications and/or good practices in order to build up an agenda dedicated to the management for sustainability. The domain of sustainability, in fact, is having a huge attention both in the scientific and in the managerial debate, looking for approaches, models and techniques able to drive business decisions towards a wider consideration of the social and the environmental responsibility of the firms.

In the last two decades, the most authoritative international literature on sustainable tourism has underlined the undisputable link between the sustainability of tourism and the presence of an adequate strategy, capable of defining limits, rules and good practices both for tourists, and for tourist firms. Concepts such as "limit", "regulation", "overtourism", "flow control", "green strategies \& behaviours", have acquired a new centrality in the field of both the destination and the firm's management. The future of tourism, and, above all, the preservation and valorisation of territories, landscapes, cultures and tourist attractions, depends always more often on the capacity to develop coherent and appropriate strategies, able to combine the three vertices of the sustainability triangle: economy, society and environment are not in competition, but must be interconnected in a wide approach to the management of tourism.

The special issue received various contributions, of which 7 were deemed eligible for publication in the Sinergie Journal, after a double-blind referee procedure.

The contributions proposed by the authors can be framed in two macrothematic strands, which reflect distinct perspectives of investigation. Most of the papers take the perspective of the tourist destination, providing useful food for thought and study on the role of environmental resources (Franch et al., and Goffi et al.), of the local community (Basile et al.), and of events (d'Angella et al.) for the competitiveness of the territories with a tourist vocation. A territorial perspective is also adopted in the study by Cerquetti and Montella, who seek to link the sustainability needs of the Italian museum system with the objectives set by the UN 2030 agenda.

Only in one paper the research focuses its attention on social responsibility strategies pursued by hotel companies, trying to understand the link between the orientation towards sustainability and the ability to attract customers. The paper to which we refer follows next.

Stefano Franco, Matteo Caroli and Giacomo Del Chiappa, in their paper "The impact of hotel sustainability practices on tourist intentions to book hotel rooms", aim to understand whether the hotels' commitment to social sustainability practices is a factor that influences the tourists' intentions to book a hotel room. The empirical analysis was based on a between-subjects experimental approach, applied to a sample of 451 Italians. A t-test and a multiple regression analysis were then adopted to measure whether social responsibility affects the customers' intentions to book. Findings show that customers are more willing to book rooms at hotels committed to social responsibility activities than at those that are not, and suggest to hotel marketers to undertake social responsibility practices to elicit consumers' intentions to make hotel reservations, thus sustaining hotel performance and local community wellbeing. 
The theme of sustainability of tourist destinations is what unites the subsequent research contributions.

Mariangela Franch, Paola Masotti, Federica Buffa and Francesca Meo, in their research paper "The role of the cable car in sustainable mobility: management choices and an assessment of environmental sustainability. The Trento-Monte Bondone project", analyse the best context and practices for the design of a sustainable cable car mobility, taking two benchmarks in the alpine area. As a result, a number of key dimensions and best practices for the implementation of this kind of projects were identified, with regard to their sustainability. A particularly innovative feature of this research is the application of the LCA (Life Cycle Assessment) methodology for the calculation of the environmental impact of Trento's project.

Gianluca Goffi, Linda Osti and Oswin Mauer, in their paper "Quality and preservation of local resources in coastal destinations from a tourists' perspective. The case of Hua Hin", investigate whether the quality and preservation of natural and cultural resources meet tourists' expectations and if they have an influence on their satisfaction and re-visiting intentions. To discuss this topic, a quantitative questionnaire was administered to European tourists in Hua Hin, one of the most visited coastal destinations in Thailand. To identify and analyse possible effects, the importanceperformance analysis, principal component analysis and structural equation modelling have been employed. Results show that the visitors' expectations in terms of quality and preservation of local resources are not adequately met, thus should be improved. Findings also show that they affect the tourists' satisfaction and intention to return. In this sense, the study suggests that the quality and preservation of local resources are issues on which coastal destinations in developing countries should concentrate and invest in order to meet a growing tourists' demand for sustainability.

Gianpaolo Basile, Mario Tani, Mauro Sciarelli and Maria Antonella Ferri, in "Community participation as a driver of sustainable tourism. The case of an Italian village: Marettimo Island", investigate an often-overlooked aspect in the debate on the sustainability and competitiveness of tourist destinations: the role of the local community, using the case study of the Island of Marettimo, a small village in the south of Italy. In line with the literature, the research highlights that community participation in a destination is crucial for the creation of an enjoyable tourism offer for both tourists and residents, fostering experiential value creation processes linked to the enjoyment of authentic and valuable experiences for tourists, economic and social for the residents of the destination, which will benefit from the positive word of mouth of visitors. The original character of the work is found in highlighting the strategic nature of the role of community participation particularly in those areas with environmental and anthropological resources that can create tourist place attachment but, at the same time, are characterized by depopulation and limited welfare conditions as well. These localities are often qualified as marginal, while thanks to their capacity for social innovation based on the widespread involvement of stakeholders, they can become one of the main factors of differentiation and competitiveness of regional and national tourist destinations. 
sinergie

Vol. 39, Issue 1, 202

Francesca d'Angella, Martha Friel, Angelo Miglietta, and Ruggero Sainaghi, in their work "Cultural events for a sustainable tourism development in urban destination: the case of the Milan's week", highlight the role of the small cultural events for the sustainable development of destinations, helping to provide a more complete vision of the role of events in cities, where the focus is often exclusively on large events, neglecting micro-events. The research indicates the impact generated by a series of micro-medium cultural events in an urban destination (Milan) both on the performance of the hotels and on the seasonal structure in order to promote sustainable tourism development. The empirical survey used a mixed method, combining a quantitative analysis of the daily trend of a destination with a desk analysis of press interviews with local stakeholders. The paper shows that small cultural events in the city of Milan play a positive role not only in terms of their ability to attract large flows of overnight visitors, but rather in terms of the attractiveness of the offer for specific segments of high-value tourists. Furthermore, the study reveals that the events also play an important role on sustainable urban development in terms of inclusiveness and the promotion of cognitive capital, two central aspects for positioning Milan as a lively and attractive city in the international cultural tourism segment.

Mara Cerquetti and Marta Maria Montella, through their paper "Meeting Sustainable Development Goals. The case of the National Museum System (Italy)", start from the observation that the literature on sustainable management processes of museums and cultural heritage is still scarce, and focus their attention on the issue by investigating whether and how museum evaluation systems currently take sustainability into account. The research, through a conceptual approach, compares the Sustainable Development Goals of the UN 2030 agenda with the uniform minimum quality levels for museums, established by the Italian government to activate the Italian National Museum System. The study shows that sustainability is an integral component of measuring quality and performance in museums, highlighting the need for a holistic managerial approach that engages external stakeholders and integrates other measurement tools. In particular, seven of the 17 objectives set by the 2030 Agenda are confirmed in the Italian legislation, which includes sustainability principles and objectives, especially in the area that analyzes communication and relations with the public, the region and the stakeholders. The standards and objectives set out in this area are consistent with the goals for social and economic inclusion, which are a crucial component of sustainable development and the museum mission alike. The paper highlights that the Italian museum evaluation system only incorporates the social and economic dimensions of sustainability but is not yet aware of the importance of the environmental challenges.

Finally, Giulia Cambruzzi, Umberto Martini, Massimo Morellato and Federica Buffa, in their manuscript titled "The challenge of sustainable ski area management: the New Zealand club fields model between experience and sense of place", pose an interesting exercise of learning and knowledge transfer for ski areas management, taken from the management model of the Club Fields, in New Zealand, and its potential application in some Alpine 
ski areas in Europe. This possible synergy, as a source of innovation, deals with critical aspects such as climate change and sustainability (considering its triple bottom line), together with its compatibility with the authenticity of tourists' experiences. As a result, it provides some recommendations for improving the management of the ski destinations that potentially could be beneficiaries of the findings of this piece of research.

From a transversal reading of the various studies, it emerges that the paradigm of sustainability represents a fundamental vision and guides the strategies of tourist destinations and businesses. The proposed studies have in fact further highlighted the importance of making the economic aims of tourist actors converge with the ecosystemic and social constraints of the territories. In fact, the competitiveness of tourist destinations and hotel companies too is based on the full satisfaction of tourists, which depends on the quality of social relations with residents and on the positive evaluation of environmental sustainability practices incorporated in tourist offers.

At the end of this short presentation of the special issue, as guest editors we warmly thank all the authors who have contributed to feed the monographic issue of Sinergie Journal, enriching the debate on tourism and sustainability. The debate is still very fluid and open, also in light of the health emergency due to the Covid 19 pandemic, whose impact on the economic and social sustainability of tourism at the moment is dramatically negative. For this reason, all the players in the tourism value system are called upon to innovate the traditional business models, taking into account the new trends in demand and above all the importance of behaviors attentive to the ecosystem balance on which people's health is based, a prerequisite important for the rebirth of tourism worldwide.

\section{Academic or professional position and contacts}

Tonino Pencarelli

Full Professor of Management

University of Urbino - Italy

e-mail: tonino.pencarelli@uniurb.it

Umberto Martini

Full Professor of Management

University of Trento - Italy

e-mail: umberto.martini@unitn.it

Alfonso Vargas-Sánchez

Full Professor of Strategic Management

University of Huelva - Spain

e-mail:vargas@uhu.es
Tonino Pencarelli

Alfonso Vargas-Sánchez

Guest editorial:

Management, social

responsibility and

sustainability in tourism: issues and practices 